\title{
Avaliação Institucional: uma Análise da Literatura Científica e da Legislação Acerca da Autonomia das Faculdades
}

\author{
Institutional Assessment: an Analysis of Scientific Literature and Legislation about \\ Colleges Autonomy
}

\author{
Rosa Maria da Rocha Neves Machado
}

Universidade Cidade de São Paulo, Programa de Pós-Graduação Stricto Sensu em Formação de Gestores Educacionais. SP, Brasil. *E-mail: rosacampus_sec@hotmail.com

\begin{abstract}
Resumo
Este estudo reflete sobre a dinâmica das leis e normas educacionais impostas à gestão administrativa e acadêmica das Instituições de Educação Superior, especialmente, no que tange à autonomia e à busca por notas nos procedimentos avaliativos institucionais. O tema revela contradições e indefinições, que fomentaram o questionamento: partindo-se do princípio de que a avaliação institucional, orientada pelas perspectivas do SINAES, está parametrizada às Universidades, até que ponto as Faculdades, ditas como não Universitárias, a quem se aplica a mesma avaliação, têm sua identidade institucional considerada no processo de avaliação institucional, dando-lhes condições de autonomia? O objetivo deste artigo foi analisar o impacto da aplicação do instrumento de avaliação institucional emitido pelo Inep nas faculdades, verificando a adequação da realidade institucional, averiguando até que ponto esse instrumento de avaliação considera a diversidade institucional e/ou contribui para definir seu perfil institucional, favorecendo a emancipação e a autonomia. A metodologia se organizou mediante a realização de um levantamento bibliográfico e qualitativo, incluindo-se estudos da documentação normativa. Concluiu-se que a aplicação da avaliação institucional do Inep apresenta características subjetivas e de desigualdade, especialmente, porque configura contradições quanto à nota do Enade como um fator de renovação imediata de atos autorizativos. Há proposta de mudança dessa situação, mas, igualmente, essa está atrelada às questões avaliativas e de resultados alcançados pelas IES.
\end{abstract}

Palavras-chave: Educação Superior. SINAES. INEP.

\begin{abstract}
This study reflects about the dynamics of laws and educational norms imposed on the administrative and academic management of Higher Education Institutions, especially regarding autonomy and the pursuit of grades in institutional evaluation procedures. The theme reveals contradictions and uncertainties that fomented the question: Assuming that the institutional evaluation, guided by theperspectives of SINAES, is parameterized to the universities, to what extent do the colleges, said as non-university, to which it applies same evaluation, have their institutional identity been considered in the institutional evaluation process, giving them autonomy conditions? The objective of this paper was to analyze the impact of the application of the institutional assessment instrument issued by Inep on the colleges, verifying the adequacy of the institutional reality, ascertaining to what extent this assessment instrument considers institutional diversity and / or contributes to defining its institutional profile, favoring its emancipation and autonomy. The methodology was organized by conducting a bibliographic and qualitative survey, including studies of normative documentation. It was concluded that the application of Inep institutional evaluation presents subjective and inequality characteristics, especially because it configures contradictions regarding the Enade punctuation as a factor of immediate renewal of authorizing acts. There is a proposal to change this situation, but it is equally associated with the evaluation and results issues achieved by the HEIs.
\end{abstract}

Keywords: Higher Education. SINAES. INEP.

\section{Introdução}

A Lei $n^{\circ} 10.861$, de 14 de abril de 2004, instituiu o Sistema Nacional de Avaliação da Educação Superior (SINAES) (BRASIL, 2004a) com o objetivo de assegurar o processo nacional de avaliação das Instituições de Educação Superior (IES), dos cursos de graduação e do desempenho acadêmico de seus alunos e, ainda, tem como uma de suas finalidades a afirmação da autonomia e da identidade institucional.

A faculdade isolada é a nomenclatura dada à faculdade sem vínculos com Universidades, que atua sem parcerias e com propostas curriculares em uma ou mais áreas do conhecimento. As prerrogativas de autonomia são dadas às
Universidades e Centros Universitários. Entretanto, esse tipo de credenciamento institucional depende de funcionamento regular e com padrão satisfatório de qualidade. Ainda assim, as IES são credenciadas, originalmente, como faculdades.

Pese a finalidade do SINAES voltada para a autonomia e identidade, também é preciso considerar que, embora uma Faculdade seja considerada pela LDB, Lei no 9.394/96, uma IES, não sendo universitária, tem vetada sua autonomia. Somente IES universitárias têm autonomia assegurada no Art. 53 da LDB, e liberdade para reformar estatutos, regimentos, conferir títulos de grau e diploma, administrar recursos, receber doações e operações financeiras, criar cursos, organizá-los 
ou extingui-los, delimitar quantidade de vagas, determinar currículos, planos, projetos e programas (BRASIL, 1996).

No cotidiano da gestão e da organização de uma IES, muitos são os processos que tramitam entre a Instituição e o MEC, e várias são as dificuldades nessa relação, principalmente, no que diz respeito a um tempo razoável para a conclusão de processos de regulamentação abertos pelas IES, por meio do sistema e-MEC. A partir da implantação do sistema e-MEC, toda tramitação de processos entre as IES e o MEC passa a ser feita com a utilização dessa ferramenta, como atos autorizativos para oferta de cursos, de credenciamento de IES, de recredenciamento das Instituições, entre outros processos. Contudo, poucas melhoras houveram acerca da agilidade na finalização das petições. Mesmo com a facilidade da abertura de demandas por meio eletrônico junto ao MEC, até a sua conclusão com a publicação junto ao Diário Oficial, os processos continuam sendo lentos e apresentam vários entraves.

Quando não há agilidade na tramitação de um processo, e ele permanece por meses sem movimentação junto ao eMEC, causa-se um grande impacto nas IES, uma vez que essas ficam na dependência de autorização prévia por parte do MEC, por exemplo, como um processo de autorização de um curso de graduação de uma faculdade isolada que, para iniciar sua oferta, apenas poderá abrir o processo seletivo e criar turmas tendo recebido a autorização. A falta de autonomia das faculdades isoladas, portanto, não lhes permite criar cursos, já que estão totalmente dependentes da autorização prévia do MEC.

Foi a partir dessa contextualização que surgiu a problematização desta pesquisa: por que a faculdade isolada é ignorada pela legislação educacional, tratada como exceção ou como inferior, embora tenha sido a origem de muitas das atuais universidades? As faculdades se adequam aos instrumentos de avaliação externa (INEP), desenvolvendo um plano de gestão, atendendo aos preceitos da lei, preceitos que são necessários para se manter no mercado educacional e funcionar plenamente. Obter boas notas em uma avaliação do SINAES não deveria aportar autonomia às faculdades, uma vez que essas se adequaram a uma série de exigências? Diante disso, a questão sobre a qual se fundamentou esta pesquisa, foi: partindo-se do princípio de que a avaliação institucional, orientada pelas perspectivas do SINAES, está parametrizada às Universidades, até que ponto as faculdades isoladas, ditas como não universitárias, a quem se aplica a mesma avaliação, têm sua identidade institucional considerada no processo de avaliação institucional, dando-lhes condições para sua emancipação? Esta problematização, em si mesma, justifica a pesquisa desenvolvida, tanto academicamente, quanto no escopo da sociedade e, em função da importância de estudos sobre evolução da Educação Superior, trata-se também de uma análise, que se justifica acadêmica e socialmente.

Nesse contexto, tomou-se como objetivo: analisar o impacto da aplicação do instrumento de avaliação institucional emitido pelo Inep nas faculdades, verificando a adequação da realidade institucional e averiguando até que ponto esse instrumento de avaliação externa favorece a emancipação e autonomia das faculdades. Para que fosse possível chegar a essa análise plenamente, também se entendeu como necessário apresentar o histórico de implantação das Universidades no Brasil e o contexto atual das normativas associadas à Educação Superior e às IES; apresentar o sistema de avaliação da Educação Superior no Brasil, o modelo de aplicação e a utilização de seus resultados no mercado educacional; e examinar os impactos da aplicação dos instrumentos de avaliação institucional externa (INEP), voltado para a faculdade isolada, aderente ao sistema avaliativo.

\section{Material e Métodos}

Goldenberg (2004) afirma que, na pesquisa qualitativa, a preocupação do pesquisador não é com a representatividade numérica do grupo pesquisado, mas com o aprofundamento da compreensão de um grupo social. Viu-se a necessidade de realizar um embasamento teórico com apoio em textos, autores e referências bibliográficas, incluindo análises de teorias ou abordagens existentes, com o objetivo de coletar informações, a fim de aferir o que foi produzido, e a partir da junta de material, analisar e compreender o objeto estudado.

Este trabalho partiu, portanto, de uma abordagem qualitativa, e os estudos foram desenvolvidos por análise documental, envolvendo a legislação. Foi realizada uma pesquisa bibliográfica com a finalidade de buscar e avaliar criticamente a produção sobre o tema pesquisado, sem se delimitar, no que toca ao referencial de suporte teórico, uma data limite para publicações, o que envolveu a análise da literatura, conduzindo a reflexões a respeito do objeto de estudo, correlacionando aspectos que viessem a contribuir com o desenvolvimento da investigação. Ressalta-se que o presente artigo é parte de uma dissertação desenvolvida no âmbito de um mestrado em Educação, especificamente, em torno da formação de gestores educacionais.

\section{Resultados e Discussão}

\subsection{Surgimento das IES}

No século XIX, muitas IES se apresentavam com características liberalistas, voltadas para um grupo específico da sociedade, os mais privilegiados, os que tinham condições de frequentar a Educação Superior no Brasil. Nesse sentido, Stallivieri (2006, p.3) afirma:

A Universidade surge no Brasil no começo do Século XIX, como resultado da formação das elites que buscaram a educação principalmente em instituições europeias durante o período de 1500 a 1800 e que retornaram ao país com sua qualificação. Elas surgem em momentos conturbados e são basicamente fruto da reunião de institutos isolados ou de faculdades específicas, fato que lhes deu uma característica bastante fragmentada e frágil. 
No período compreendido entre 1891 a 1910 foram criadas 27 faculdades, entre essas, em 1896, a primeira de natureza privada do país, a Escola de Engenharia Mackenzie, comunitária e confessional, categoria administrativa utilizada pelo MEC até a presente data. A partir do século XX, algumas faculdades isoladas existentes se uniram, dando início à implantação de algumas Universidades. Especificamente, em 1909, foi implantada a Universidade da Amazônia, no Maranhão, e depois dessa, foram implantadas, em 1912, a Universidade Federal do Paraná, em Curitiba; em 1920, a Universidade Federal do Rio de Janeiro. Também foram criados novos Institutos Tecnológicos e Centros de Pesquisa, sendo que todas essas instituições surgiram do esforço e da busca por recursos humanos próprios, sem auxílio governamental (HUMEREZ; JANKEVICIUS, 2015).

A Universidade do Rio de Janeiro merece destaque, posto que foi a primeira legalizada pelo Governo Federal, com autonomia didática e administrativa. O Decreto $\mathrm{n}^{\circ} 14.343$, de 7 de setembro de 1920 havia instituído a Universidade do Rio de Janeiro, reunindo a Escola Politécnica, a Faculdade de Medicina e a Faculdade de Direito do Rio de Janeiro, sendo dispensada de fiscalização, no Art. $1^{\circ}$ do Decreto. O Art. $3^{\circ}$ assegurava essa autonomia didática e administrativa, devendo a Universidade, entretanto, adequar sua organização aos moldes do Decreto $n^{\circ}$ 11.530, de 18 de março de 1915. As discussões, nessa época, fundamentavam-se na proposta do que seria a Universidade brasileira em termos de função, de abrangência e de concepção. Havia uma expectativa de democracia liberal, e a eleição de Getúlio Vargas, por meio do Congresso, frustrou a tendência centralizadora hegemônica e autoritária, mas essa aparente abertura se mostrou apenas um amálgama na história da Educação Superior no Brasil.

Em 1934, criou-se a USP, Universidade de São Paulo, e em 1935, a UDF, Universidade do Distrito Federal, tendo sido, esta última, fechada em 1939, consequência de seu caráter subversivo inaceitável para o controle estatal (FÁVERO, 2006). Estava instalada e mais presente que nunca a governamentabilidade pastoral, apontada por Foucaut (2006).

De acordo com Sampaio (1991), o Ensino Superior no Brasil somente adquiriu caráter universitário durante os anos 1930, contrastando severamente como os países da América espanhola, que consolidaram suas primeiras Universidades no período colonial. Conforme afirma Bortolanza (2017, p. 6): "antes do final do século XVIII, a maioria dos países latinoamericanos tinham uma ou mais universidades perfazendo dezenove ao todo e chegando a mais de trinta no século XIX, com exceção do Brasil". Humerez e Jankevicius (2015) apontam que somente, em 1934, foi implantada a primeira Universidade brasileira, baseada no tripé Ensino-Pesquisa-Extensão, a Universidade de São Paulo, USP, a partir da importação da maior parte do corpo docente. O Brasil foi o derradeiro país das Américas a consolidar uma Universidade.

Em 1940, foi criada a Universidade Católica do Rio de Janeiro (PUC-RJ). Tratou-se de um período em que a implantação de uma Universidade era possível, em termos de estrutura administrativa e didática, a partir da junção de três faculdades isoladas, a de Direito, de Engenharia e de Medicina, podendo substituir uma destas, por Educação, Ciências e ou Letras, como declaram Neves e Martins (2016).

Já nesse período, uma Universidade podia ser implantada, a partir da reunião das Faculdade de Filosofia, Direito e Economia, ou de Serviço Social. Mudanças na legislação, em 1945, haviam suprimido a necessidade de integrar as Faculdade de Engenharia ou de Medicina, que exigiam um alto investimento e eram extremamente raras, como afirmam Neves e Martins (2016). Importante ressaltar que:

Com o surto de industrialização posterior à Segunda Guerra e seu aprofundamento nos anos de 1960, consolidou-se a percepção, nos quadros dirigentes, que o Brasil necessitava de quadros profissionais com formação universitária para enfrentar o processo de desenvolvimento econômico. Em meados da década de 1960, o governo federal iniciou um processo de construção de uma rede de universidades federais, públicas e gratuitas, abarcando praticamente todos os estados da Federação. Em função desta iniciativa, em 1965 o número de matrículas cresceu, atingindo cerca de 352 mil estudantes. Destes, 56\% encontravam-se no setor público (NEVES; MARTINS, 2016, p. 97).

Entretanto, o Golpe Militar de 1964 e a instauração da Ditadura acirraram todo o processo de resistência do Governo à autonomia das Universidades e Faculdades. Surgiu um projeto desenvolvimentista baseado no autoritarismo e na internacionalização econômica, para além dos ideais de industrialização e de ocupação dos espaços vazios da era Vargas. Houve uma expansão relativa das IES, no Brasil, durante esse período, mas a expansão de vagas não era proporcional, o que mobilizou organizações estudantis, em todo o território nacional. Havia uma demanda por vagas, pelos diplomas de Ensino Superior, demanda fomentada, principalmente, pelas classes médias urbanas, que começaram a disputar promoções profissionais nos setores públicos e privados. Todas essas reivindicações também associavam críticas ao distanciamento da Universidade brasileira com a pesquisa científica. Os Governos militares estabeleceram reformas, a fim de atender às demandas do desenvolvimento brasileiro (NEVES; MARTINS, 2016).

O MEC e o Conselho Federal de Educação (CFE), indo contra a corrente da Reforma Universitária de 1968, começaram a permitir a abertura de novas Faculdades isoladas e integradas no setor privado, buscando amenizar as reivindicações, o que funcionou, já que a movimentação surgia de uma classe social que podia pagar pelo ensino que almejava.

Além disso, foi uma estratégia que permitiu que o Governo Federal controlasse seus investimentos em Educação, reduzindo as tensões públicas e, em contrapartida, evitando uma massificação da Graduação em IES públicas. Dessa forma, as políticas adotadas nas décadas de 1970 e 1980 foram orientadas para a autorização de abertura de IES privadas, e as 
IES públicas focaram mais no desenvolvimento da pesquisa e extensão, embora com número mais limitado de vagas.

A competitividade por essas vagas no Ensino Superior foi sempre inferior no ensino privado ao que se presenciava no ensino público, e o setor privado se fundamentou nas Faculdades isoladas, especialmente das áreas de Ciências Humanas e Sociais Aplicadas, em função do menor investimento em infraestrutura (NEVES; MARTINS, 2016).

Segundo Sampaio (2011, p. 29): "nos anos 1970, enquanto o setor privado crescia por meio da criação de instituições isoladas e do aumento do número de cursos e vagas oferecidos, o setor público investia em pesquisa e criava uma estrutura de regulação e de apoio à pós-graduação".

Até 1960 , o setor privado correspondia a 50,5\% das ofertas de vagas, e durante a década 1970 passou para 64,3\%.

É justamente nesse momento em que foi adotado um novo caráter para a Educação Superior privada, assumindo-se o ethos empresarial e capitalista, buscando-se lucratividade e distanciando-se do perfil anterior de IES privada, majoritariamente constituído de escolas confessionais e sem fins lucrativos (NEVES; MARTINS, 2016). Também nessa perspectiva, Sampaio (2011, p. 29) afirma que: "para um contingente cada vez maior da população, a formação superior passava a fazer parte de seus projetos de realização pessoal e de ascensão social. A iniciativa privada, atenta às demandas de novos e potenciais consumidores, respondeu de forma ágil”.

Esse novo formato de Educação Superior, mercantilizada, foi viabilizada, principalmente, pelo CFE, cujas atribuições deliberativas, normativas e de assessoramento no Ministério estão ligadas às personalidades, que têm interesses no ensino privado e na abertura de novas IES particulares, como apontaram Neves e Martins (2016). Depois de 1969, a autorização de aberturas dessas IES aumentou, solicitando-se apenas que essas cumprissem as exigências mínimas de recursos financeiros e de recursos humanos para seu funcionamento. Muitas instituições, que já vinham atuando no Ensino Médio, começaram a oferecer o Ensino Superior, uma oportunidade comercial favorável, já que as IES públicas não ampliavam as vagas.

Sampaio (2000) aponta para o fato de que na segunda metade da década de 1990 havia certa interação entre os setores público e privado no Ensino Superior brasileiro, haja vista que a própria existência do setor privado se relaciona com as condições de oferta do setor público. No entanto, entre o final da década de 1980 e o ano de 1994 aconteceu uma redução da demanda educacional superior, fruto da redução de alunos formandos do Ensino Médio, em função da retenção de conclusão, o que afetava as bases das instituições privadas, que obrigaram o setor a expandir sua atuação, geograficamente, abrindo novas IES no interior do país, ao mesmo tempo em que eram reduzidas as instituições isoladas e criadas Universidades por meio de fusões, ampliação de cursos e carreiras, aumentando-se o leque das ofertas, buscando a formação profissionalizante dos estudantes.
Isso supriu, temporariamente, a estagnação das IES privadas. Por outro lado, houve também certa pressão por transformações legislativas, já que se mostrava necessária maior flexibilidade curricular, por exemplo, e, ademais, investiu-se muito no marketing e na propaganda institucional. Em 1994, houve $24 \%$ de vagas de IES privadas, que não foram preenchidas. Nesse momento, o Conselho de Reitores das Universidades Brasileiras (CRUB) começou a aceitar dirigentes de Universidades privadas, que logo dominaram numericamente a representação, e foram criadas as associações, como a Associação Brasileira de Escolas Superiores Católicas (ABESC), a Associação Brasileira das Mantenedoras de Ensino Superior (ABMES), e a Associação Nacional das Universidades Comunitárias (ABRUC) (SAMPAIO, 2000).

Nesse contexto da década de 1990, não se pode pensar a Educação no Brasil e no Mundo à parte da consolidação da sociedade industrializada e da necessidade do momento de recuperação de uma possível crise do capitalismo, advinda dos conflitos da Guerra Fria, ou seja, a parte das bases do neoliberalismo, que se fundamentou na bandeira da assistência e equilíbrio social. Esse movimento neoliberal da economia mundial direcionou a expansão de cursos superiores privados no mundo inteiro, e no Brasil, após o ano de 1994, com a ascensão de um Governo marcadamente neoliberal, surgiu uma nova mentalidade em torno da Educação, o que, de acordo com Schwartzman (2005, p. 5), já não demonstra uma relação exclusiva com as "necessidades do mercado de trabalho por pessoas mais qualificadas", mas também com o "resultado de um fenômeno de mobilidade social e expansão dos sistemas educacionais".

A nova educação mercadológica se transforma no fundamento do capitalismo, especialmente, porque fomenta concorrência e competitividade. Mais profissionais formados, maior produtividade e, portanto, fortalecimento de livre concorrência. Uma lógica empresarial facilmente aplicável à privatização da educação (KOGA; GUINDANI, 2017).

A partir disso, a Universidade, conforme Silva e Suanno (2015, p. 24058): "busca desenvolver o processo de ensino pautado nos interesses do mercado, desenvolvendo conhecimentos técnicos e uma formação rápida". Na realidade, as mudanças do processo liberalista anterior para o neoliberalista não são tão profundas quanto a esse pensamento, o que se acentua é a ideologia implementada, voltada para o estado de bem-estar social, advinda do pós-guerra e desse embate entre socialismo e capitalismo, que chegaram ao Brasil sob a égide corporativista e a organização do trabalhador, que exerceu pressão sobre o Estado.

Assim, depois da mudança de Governo, em 1994, e da completa implementação do neoliberalismo na economia brasileira, fomenta-se novamente a expansão das ofertas dos cursos e abertura de novas IES. Em 1996, cria-se o Exame Nacional de Cursos, que propicia uma cultura de mensuração de qualidade e a ideia de autonomia das IES, o que, por uma parte, favorece essa privatização e, por outra, continua 
isentando o Estado de grandes investimentos na Educação (SÁ; MONTEIRO, 2017).

Uma das políticas adotadas a partir de então é a oferta de subsídios para as IES privadas, estabelecendo certo tipo de parceria. Aumenta-se a oferta da Educação Superior, sem que se invista, significativamente, na Educação pública. Esse processo, conforme Koga e Guindani (2017), consolidou, na década de 1990, a Educação como mercadoria, enquadrandoa dentro do setor de prestação de serviços.

Os dados apresentados pelo Inep (2017) demonstram que no ano de 2018, última sinopse divulgada pelo Instituto, havia um total de 2.448 IES no Brasil, sendo 2.152 privadas, ou seja, $87,9 \%$ das IES brasileiras são privadas, quando em 1933 eram $64,4 \%$. Além disso, o total de matrículas nesse mesmo ano foi de 8.286 .663 , sendo que $75,32 \%$ dessas foram realizadas em IES privadas, considerando cursos de graus acadêmicos diferenciados, quando em 1933 eram 43,7\% das matrículas.

\subsection{Organização Acadêmica}

De acordo com sua organização acadêmica, as instituições podem ser credenciadas como: Faculdades, Centros Universitários, Universidades ou Instituto Federal, e ainda, podem ser públicas ou privadas, de acordo com normatização do MEC, no artigo 15 do Decreto $\mathrm{n}^{\circ}$ 9.235/2017. O nível de autonomia de uma IES para abrir novos cursos ou criar vagas depende dessa organização acadêmica e, hierarquizando esta autonomia, tem-se a seguinte classificação: Universidades, Centros Universitários e Faculdades, sendo que a última depende quase que totalmente de autorização do MEC para implantação de novos cursos, mudanças regimentais, entre outros processos.

De acordo com normativas do MEC, mais especificamente a Resolução $n^{\circ} 3$, de 14 de outubro de 2010, o credenciamento inicial ocorre por meio da Faculdade, e dependendo do seu funcionamento regular, com padrão satisfatório de qualidade, poderão requerer a transformação da organização acadêmica junto ao MEC, as faculdades que tenham um funcionamento regular de, no mínimo, doze anos e os Centros Universitários de no mínimo nove anos.

Ao requerer a transformação da organização acadêmica, às Faculdades e aos Centros Universitários, eram impostas algumas condições fixadas na Resolução $n^{\circ} 3$, estipuladas no Art. $3^{\circ}$, entre as quais aquelas que já foram apontadas como determinantes da caracterização de IES, ou seja, o credenciamento como Universidade exige um terço do corpo docente em atuação de regime integral, a mesma proporção com titulação mínima de mestre, oferta mínima de $60 \%$ de cursos de Graduação já reconhecidos pelo MEC ou em processo protocolado, oferta mínima de quatro cursos de nível mestrado e dois de doutorado, reconhecidos pelo MEC, compatibilidade de Estatuto e Plano de Desenvolvimento Institucional (PDI) com a categoria da Instituição, não ter sofrido penalidades administrativas em cinco anos, e Conceito
Institucional (CI) na avaliação do SINAES superior ou igual a 4, assim como o Índice Geral de Cursos (IGC) (MEC, 2010). Nas alterações da Resolução CES/CNE no 5/2017, houve o fim da exigência de Índice Geral de Cursos (IGC) igual ou superior a quatro como condição para o credenciamento como Universidade.

O Decreto $n^{\circ} 3.860$, de 2001, revogado pelo Decreto $n^{\circ}$ 5.773, de 2006, apontava, no Art. $7^{\circ}$, que a organização das IES do sistema federal de ensino classificava essas IES como Universidades, Centros Universitários, Faculdades Integradas, Faculdades, Institutos ou Escolas Superiores, Centros Federais de Educação Tecnológica, Faculdades de Tecnologia, Institutos e Escolas Superiores. O parágrafo único afirmava que os estabelecimentos Faculdades Integradas, Faculdades, Institutos ou Escolas Superiores seriam considerados estabelecimentos isolados de Ensino Superior. Além disso, no Art. $8^{\circ}$, as Universidades estariam caracterizadas pela oferta de atividades voltadas para ensino, pesquisa e extensão.

O Art. 11 apontava que os Centros Universitários seriam IES pluricurriculares, caracterizadas "pela excelência do ensino oferecido, comprovada pelo desempenho de seus cursos nas avaliações coordenadas pelo Ministério da Educação, pela qualificação do seu corpo docente e pelas condições de trabalho acadêmico oferecidas à comunidade escolar", e as Faculdades Integradas ficaram conceituadas, no Art. 12, como "instituições com propostas curriculares em mais de uma área de conhecimento, organizadas para atuar com regimento comum e comando unificado", sendo que o Art. 13 determinava que a oferta dos Cursos Superiores nas Faculdades já era dependente de autorização prévia, sem se referir às Universidades e Centros Universitários (BRASIL, 2001)

O Decreto $\mathrm{n}^{\circ} 5.773$ de 2006, revogado pela Lei $\mathrm{n}^{\circ}$ 9.235/2017, criou certa generalização ao determinar no Art. $2^{\circ}$, que o sistema federal de ensino é composto por IES privadas e as mantidas pelo órgão federal e, no Art. 12, definindo as IES, segundo sua organização, como Faculdades, Centros Universitários e Universidades, sem, contudo, determinar um conceito específico para cada uma dessas.

A Lei n 9235/2017 mantém, no Art. 15, a descrição do Decreto $\mathrm{n}^{\circ}$ 5.773/2006, Art. 12, quanto à organização de prerrogativa acadêmica para credenciamento em Faculdades, Centros Universitários e Universidades, sendo que no parágrafo $1^{\circ}$ determina que as instituições privadas deverão ser credenciadas, inicialmente, como Faculdades, e a alteração da organização é feita mediante recredenciamentos. Nesse suposto novo modelo de organização, conforme o Art. 16, as Faculdades podem solicitar recredenciamento com a mudança de organização para Centro Universitário se atenderem os requisitos:

I - um quinto do corpo docente estar contratado em regime de tempo integral;

II - um terço do corpo docente possuir titulação acadêmica de 
mestrado ou doutorado;

III - no mínimo, oito cursos de graduação terem sido reconhecidos e terem obtido conceito satisfatório na avaliação externa in loco realizada pelo Inep;

IV - possuírem programa de extensão institucionalizado nas áreas do conhecimento abrangidas por seus cursos de graduação;

$\mathrm{V}$ - possuírem programa de iniciação científica com projeto orientado por docentes doutores ou mestres, que pode incluir programas de iniciação profissional ou tecnológica e de iniciação à docência;

VI - terem obtido Conceito Institucional - CI maior ou igual a quatro na avaliação externa in loco realizada pelo Inep, prevista no $\S 2^{\circ}$ do art. $3^{\circ}$ da Lei $n^{\circ} 10.861$, de 14 de abril de 2004; e

VII - não terem sido penalizadas em decorrência de processo administrativo de supervisão nos últimos dois anos, contado da data de publicação do ato que penalizou a IES (BRASIL, 2017).

Para requerimento de mudança de organização para Universidade, as Faculdades precisam, além desses requisitos, de acordo com o Art. 17, ter um terço do corpo docente com contratação em regime integral, $60 \%$ de cursos reconhecidos ou protocolados e com CI satisfatório, ter quatro cursos de Mestrado e dois de Doutorado reconhecidos pelo MEC, não ter sofrido penalizações administrativas em dois anos (BRASIL, 2017).

Além disso, a Portaria do MEC n 21, de 2017 declara que a classificação da organização da IES é decorrente da sua natureza jurídica. Ainda, a mesma Portaria do MEC, em seu Anexo Manual de Conceitos para as Bases de Dados do Ministério da Educação sobre Educação Superior, determina em seu item 5.1 que quanto à abrangência de atuação das IES, as Faculdades são descritas como:

instituições não universitárias de Educação Superior, com propostas curriculares em mais de uma área do conhecimento, organizadas sob a mesma direção e regimento comum, com a finalidade de formarem profissionais, podendo ministrar os cursos deste nível e nas diversas modalidades, desde que credenciadas pelo poder competente (BRASIL, 2017).

Os Centros Universitários são descritos em 5.2 como dotados de autonomia no que toca à criação de vagas e cursos em sede, podendo solicitar credenciamento para atuação extra sede, desde que tenha um terço do corpo docente como mestre e doutores e um quinto em regime de tempo integral. As especificações para a Universidade, em 5.3, acrescentam um terço do corpo docente em regime integral e oferta de formação profissional em pesquisa e extensão, dominando o cultivo do saber e, ademais, "são instituições que se caracterizam pela indissociabilidade das atividades de ensino, de pesquisa e de extensão" (BRASIL, 2017).

É importante apontar que as Faculdades podem emitir o certificado de cursos Lato Sensu, mas não podem emitir diplomas de graduação e pós-graduação Stricto Sensu, em função de sua falta de autonomia. Nesses últimos casos, como já foi apontado anteriormente, deverão recorrer às Universidades, segundo as indicações do próprio MEC.
Embora a Educação Superior tenha aumentado sua oferta durante o século passado, na década de 1990, houve uma segunda grande expansão, já baseada no neoliberalismo e na instauração da educação como mercadoria, segundo apontaram Schwartzman (2005), Koga e Guindani (2017), Ferronato (2016), e Silva e Suanno (2015). Desenvolver o mercado da educação se tornou um fator importante das políticas públicas brasileiras, seguindo a mesma mentalidade liberal de redução de gasto público e, ao mesmo tempo, expansão da oferta de ensino. $\mathrm{O}$ aluno se torna cliente. A educação se torna oferta de serviços.

\subsection{Legislação}

Em 1996, a Lei no 9394/96 (BRASIL, 1996), LDB atual, regulamenta ou reformula o Sistema Educacional Brasileiro, desde a Educação Básica até a Educação Superior. Essa prevê, no Art. 45, que a Educação Superior será ministrada em Instituições, públicas ou privadas, com diferentes graus de abrangência ou especialização. No caso das instituições públicas que são mantidas pelo poder público Federal, Estadual ou Municipal, e financiadas pelo Estado, e nessas IES não é permitida a cobrança de matrícula ou mensalidade.

No Art. 46, a nova LDB afirma que o reconhecimento, a autorização dos cursos e o credenciamento das IES serão renovados, periodicamente, dentro dos prazos delimitados, associados à avaliação institucional e, no parágrafo $1^{\circ}$, aponta-se que as IES terão prazo para resolução de problemas identificados pela comissão de avaliação, sendo que, no caso de que as deficiências não sejam sanadas, poderá haver desativação dos cursos, suspensão das prerrogativas de autonomia e até o descredenciamento da IES.

Além disso, consta no parágrafo $3^{\circ}$ que se a IES privada descumprir o que está determinado no parágrafo $1^{\circ}$, as vagas ofertadas também podem ser restringidas e se pode acarretar a suspensão de oferta de cursos, sendo possível, no parágrafo $4^{\circ}$, facultado ao MEC, aplicar penalidades e, inclusive, multas, com o fim de resguardar o interesse dos estudantes (BRASIL, 1996). É importante observar que em nenhum lugar da legislação brasileira consta quais seriam esses interesses estudantis. Subentende-se que se referem à educação de qualidade, ou fatores semelhantes, mas não se pode analisar a lei sem perceber que, em muitos momentos, há uma dubiedade ou falta de objetividade na argumentação apresentada.

Outro fator significativo é que no Art. 48, a LDB (BRASIL, 1996) declara que os diplomas serão expedidos por Universidades e, no caso das IES não Universitárias, esses deverão ser registrados por alguma Universidade, que será indicada pelo MEC. Nesse sentido, o Art. 52 caracteriza as Universidades como Instituições "pluridisciplinares de formação dos quadros profissionais de nível superior, de pesquisa, de extensão e de domínio e cultivo do saber humano" (BRASIL, 1996), que realizem produção intelectual fundamentada em estudo sistemático e cujos temas 
sejam relevantes científica e academicamente, regional e nacionalmente. Para além das determinações de pesquisa apontadas nesse inciso 1 , o inciso seguinte afirma que uma Universidade necessita ter um terço de seu corpo docente titulado no mínimo como mestre, e um terço desses recursos humanos deverá atuar em regime integral. Por outro lado, ao contrário das leis mais antigas, facultou-se a criação de uma Universidade mediante múltiplos campos de saber, e essas podem ser registradas a partir dos requisitos do Art. 48 .

As Universidades têm sua autonomia assegurada em lei, no Art. 53, e têm liberdade para reformar estatutos e regimentos, conferir títulos como grau e diploma, administrar seus recursos, receber doações e outras cooperações financeiras, criar cursos, organizá-los ou extingui-los, delimitar a quantidade de vagas, segundo as capacidades institucionais, tudo desde que seguidas as normas da União, além de poderem determinar os currículos dos cursos, planos, projetos e programas voltados para a produção artística, pesquisa científica e extensão (BRASIL, 1996).

O Decreto $\mathrm{n}^{\circ}$ 9.235, de 2017, o mais atual acerca de alguns pontos das IES, aborda também os cursos Lato Sensu e modalidades de ensino, presencial e à distância, dentro do sistema federal de ensino (BRASIL, 2017). Para fins de explicitação, o Art. $2^{\circ}$ determina que o sistema federal de ensino é compreendido de IES federais e IES mantidas e criadas pela inciativa privada com a consolidação de pessoa jurídica de direito privado, além dos órgãos federais de Ensino Superior.

De acordo com o supracitado decreto, a regulação das IES ocorre por meio de atos autorizativos para funcionamento e para ofertas de cursos, e no parágrafo $1^{\circ}$ do Art. $1^{\circ}$ apresenta que são estabelecidos esses atos autorizativos, "a fim de promover a igualdade de condições de acesso, de garantir o padrão de qualidade das instituições e dos cursos e de estimular o pluralismo de ideias e de concepções pedagógicas e a coexistência de instituições públicas e privadas de ensino". Os atos autorizativos se fundamentam na supervisão e na avaliação das IES, sendo que a supervisão acontece por meio das ações corretivas ou preventivas, buscando o cumprimento das normas gerais de Educação Superior, conforme o parágrafo $2^{\circ}$ do mesmo artigo. Esses atos autorizativos, segundo o Art. 10, constituem credenciamento e recredenciamento de IES, autorização, reconhecimento e renovação do reconhecimento dos cursos superiores. Também carecem de aditamento, conforme o Art. 12, a autorização para aumento de vagas, descredenciamento e extinção de curso, de faculdades e unificação de faculdades. Importante notar que as IES com autonomia, as universitárias, apenas se enquadram nesse artigo no que toca ao aumento de vagas em cursos de Direito e Medicina. Esses atos autorizativos são renovados periodicamente (BRASIL, 2017).

A avaliação, que condiciona o funcionamento das IES, ocorre sob a responsabilidade do SINAES e tem um suposto caráter formativo, constituindo-se, segundo o parágrafo $3^{\circ}$, do Art. $1^{\circ}$, "referencial básico para os processos de regulação e de supervisão da educação superior, a fim de promover a melhoria de sua qualidade" (BRASIL, 2017), ou seja, os atos autorizativos estão submetidos aos resultados da avaliação.

Nesse contexto, a Lei n ${ }^{\circ} 10.861$, de 2004, institui o SINAES, afirmando, no Art. $2^{\circ}$, inciso I, que a "avaliação institucional, interna e externa", deve contemplar "a análise global e integrada das dimensões, estruturas, relações, compromisso social, atividades, finalidades e responsabilidades sociais das instituições de educação superior e de seus cursos", e, no inciso III, assegura que deve haver "respeito à identidade e à diversidade de instituições e de cursos".

No entanto, a lei também afirma que os procedimentos avaliativos serão a base para recredenciamentos e manutenção das atividades das IES, sendo avaliadas, inclusive, as políticas de pessoal adotadas pelas IES, sua estrutura física, e apontando o Enade como meio de se aferir se os conteúdos programáticos estão sendo bem absorvidos pelos estudantes (BRASIL 2004a). Isso significa que para além da análise burocrática enfrentada pelas IES, o comportamento estudantil no que toca a sua própria aprendizagem é de responsabilidade da IES, servindo como parâmetro para a continuação da prestação de serviços educacionais de nível superior.

O Decreto $\mathrm{n}^{\circ}$ 9.235/2017 também determina as competências do Ministro de Educação do Estado e do MEC, sendo que o primeiro deverá homologar os pareceres recebidos do CNE com pedidos de descredenciamento, credenciamento ou recredenciamento das IES, assim como qualquer parecer vindo do CNE e as homologações da Comissão Nacional de Avaliação da Educação Superior (CONAES), devendo, ainda, expedir normas e execuções para que as leis sejam executadas, no âmbito estadual, podendo, no máximo, reenviar os pareceres para reavaliação e apreciação do CNE. Mesmo que os atos homologatórios dos Ministro estadual sejam irrecorríveis (BRASIL, 2017), deve-se ter em conta que o são para as Instituições, não para o CNE.

Ao MEC cabe o exercício da supervisão e da regulação do sistema de ensino federal, enquanto ao CNE compete ao exercício das atribuições deliberativas e normativas, bem como assessoramento ao Ministro de Estado da Educação acerca das regulações e supervisão, recordando-se que é o próprio CNE quem julga os recursos a esse dirigidos e, após suas análises, propõe ao MEC os pontos julgados acerca da legislação da Educação Superior (BRASIL, 2017).

O Art. $7^{\circ}$, do Decreto $\mathrm{n}^{\mathbf{o}} 9.235 / 2017$, aponta as competências do Instituto Nacional de Estudos e Pesquisas Educacionais Anísio Teixeira (INEP), nas quais se apresentam todas as ações destinadas ao procedimento avaliativo de IES, de cursos e de estudantes, o Exame Nacional de Desempenho dos Estudantes (ENADE), atuando como planejador, coordenador, operacionalizador e avaliador nesses aspectos, proporcionando, ainda, a alimentação das bases de dados oficiais.

O INEP preside a comissão técnica de avaliação das IES in 
loco, e é esse mesmo quem elabora os instrumentos avaliativos das IES, passando pela aprovação do MEC (BRASIL, 2017). Recorde-se que, conforme a Lei $\mathrm{n}^{\circ} 10.870$, de 2004, para que aconteça a avaliação in loco, o Art. $1^{\circ}$ institui uma taxa em favor do Inep, "pelas avaliações periódicas que realizar, quando formulada solicitação de credenciamento ou renovação de credenciamento de instituição de Educação Superior e solicitação de autorização, reconhecimento ou renovação de reconhecimento de cursos de graduação". O valor da taxa é variável, a partir da quantidade de habilitações e avaliadores necessários, mas a quantia de $\mathrm{R} \$ 6.960,00$ é estabelecida no Art. $3^{\circ}$, acrescida de $\mathrm{R} \$ 3.480,00$ por avaliador. O parágrafo $3^{\circ}$, do Art. $3^{\circ}$, aponta que o valor recebido pelo Inep (mínimo de $\mathrm{R} \$ 10.000$ por visita) é, exclusivamente, para custear a visita de avaliação. As Universidades têm prazo de dez anos para renovação de cursos e de credenciamento institucional. As IES não universitárias têm prazo de cinco anos (BRASIL, 2004b).

Ainda, o Decreto $\mathrm{n}^{\mathrm{o}}$ 9.235/2017 determina as competências do CONAES no Art. $8^{\circ}$, sendo que, basicamente, atua junto ao Inep, no que toca ao procedimento avaliativo, já que é a CONAES a responsável por avaliar os procedimentos utilizados na avaliação, determinar quais cursos de quais IES estarão submetidos ao Enade no ano seguinte, concretizar os relatórios e, ademais, propor ações para o desenvolvimento da Educação Superior no país, a partir das suas análises feitas (BRASIL, 2017).

Além desses fatores, cabe ressaltar que a Portaria $n^{\circ} 21$ do MEC, do ano de 2017, determinou a implementação do sistema e-MEC e, no Art. 17, afirma que cabe às Diretorias de Tecnologia da Informação do MEC, por meio da Secretaria de Regulação e Supervisão da Educação Superior (Seres) e do Inep, a sua execução operacional, bem como a realização das atividades de funcionamento do sistema, buscando solucionar quaisquer problemas operacionais. No Art. 18 fica determinado o cadastro dos cursos das IES por meio do e-MEC, que também é consolidado como base de dados de Cursos e IES, fornecendo consulta pública, independentemente, do sistema de ensino da IES, a fim de se manter uma estatística da Educação Superior. A intenção

é que o e-MEC permita interoperabilidade eletrônica com fluxo informacional atualizado, também na tentativa de se evitar duplicação de informações. A responsabilidade pelos cadastros recai, conforme o Art. 23, sob a Seres, devendo essa realizar todas as atualizações necessárias com consistência de dados (MEC, 2017).

O que deve ser observado, no contexto da legislação atual, é que as Faculdades são em número muito superior aos Centros Universitários e as Universidades, sendo que há atualmente 2.020 Faculdades, e 428 IES Universitárias. Mesmo que as matrículas aconteçam, majoritariamente, nessas IES Universitárias, à exceção do bacharelado que apresentou maior número de matrícula nas Faculdades que nos Centros Universitários, mas, ainda assim, em número inferior às Universidades, o atendimento que as Faculdades dão aos estudantes é, consideravelmente, alto, chegando a mais de 2 milhões de alunos matriculados em 2017. A grande maioria das Faculdades é de natureza privada, como foi apontado, e de 2.020 Faculdades existentes, 92,97\% são privadas, e $24,98 \%$ de todas as matrículas efetuadas estão concentradas nas Faculdades (INEP, 2017).

No ano de 2019, as discussões acerca da Educação Superior, verificação de qualidade de ensino e outros fatores, que têm sido levantados, acabaram gerando a Portaria no 748/2019 (MEC, 2019b), que instituiu, em agosto, a Comissão de Assessoramento para Revisão dos Processos Avaliativos, Instrumentos e Técnicas de Coleta de Dados e Indicadores da Educação Superior do Inep. A comissão, como seu nome já indica, foi criada para revisar e propor aperfeiçoamento de estatísticas, indicadores, processos avaliativos, metodologia do processo avaliativo dos estudantes, além de propor estratégias e caminhos metodológicos, capazes de expressar a qualidade em termos absolutos, e outras questões que já se configuravam responsabilidade do INEP e da Diretoria de Avaliação da Educação Superior (DAES).

A Comissão será coordenada pela DAES e, também, estará encarregada de capacitar e formar os servidores da própria DAES. A comissão deverá atuar, ainda, estritamente conforme as diretrizes da DAES, seus membros receberão pagamentos e despesas de viagens custadas pelo Inep e, finalmente, conforme o Art. $3^{\circ}, \S 2^{\circ}$, “os membros serão indicados pelos Gabinete e Coordenações-Gerais da Diretoria de Avaliação da Educação Superior - DAES e nomeados pelo Presidente do INEP em ato específico" (MEC, 2019b).

Fundamentalmente, acerca dessa medida legislativa, o que se pode acrescentar é que se trata da criação de mais um órgão que onera a máquina pública, para a realização de atividades que já eram cumpridas, instituindo-se cargos indicados, que cumprirão todas as decisões superiores, mas que não se sabe se, de fato, acrescentarão algo à qualidade da Educação Superior no Brasil. Nesse sentido, é relevante apontar que a Portaria $n^{\circ}$ 670/2017 já havia criado um Comitê Gestor para atuar na reconstrução, revisão e adequação das ferramentas de avaliação utilizadas pelo Inep, também sob a coordenação da DAES (SINAES, 2017), ou seja, há dois órgãos incumbidos das mesmas funções e sob a orientação da DAES.

Enquanto essa medida já foi aprovada e publicada no Diário Oficial da União, uma outra, o Parecer CNE/ CES 398/2019, aprovado desde maio de 2019 pelo CNE, ainda aguarda homologação. O Parecer 398/2019 pretende, conforme se lê nos Artigos $2^{\circ}$ e $3^{\circ}$ :

Art. $2^{\circ}$ As instituições, assim classificadas [nota máxima em dois períodos avaliativos, conf. Art.1], poderão usufruir das seguintes atribuições:

I - criar, organizar e extinguir, em sua sede, cursos de graduação e demais programas de educação superior, previstos na Lei e na legislação aplicável, obedecendo às normas gerais da União mediante aprovação do seu PDI pela Secretaria de Regulação e Supervisão da Educação Superior 
(SERES), com a dispensa de avaliação externa in loco;

II - fixar os currículos dos seus cursos e programas,

observadas as diretrizes curriculares e outras normas gerais pertinentes; III - fixar o número de vagas dos seus cursos de acordo com a capacidade institucional e com as exigências do seu meio, nos termos da legislação em vigor;

$\mathrm{V}$ - elaborar e reformar os seus estatutos ou regimentos em consonância com as normas gerais atinentes;

VI - conferir graus, diplomas e outros títulos, e registrá-los, nos termos da legislação pertinente (MEC, 2019a).

Art. $3^{\circ} \mathrm{A}$ instituição que não lograr o conceito máximo na avaliação oficial trienal, Conceito Institucional (CI) igual a 5 (cinco), permanecerá detentora das prerrogativas descritas no artigo anterior temporariamente até que, no próximo período avaliativo, consiga obter novamente o CI igual a 5 (cinco) e, caso não logre essa posição, suas prerrogativas ficarão suspensas até o próximo período avaliativo.

Dessa forma, o Parecer CNE/CES 398/2019 vem ao encontro dos principais questionamentos aqui levantados, demonstrando que se trata de uma discussão pertinente no escopo da Educação Superior, por um lado, e que existe respaldo legal para que as IES não universitárias tenham direito à autonomia dispensada apenas às IES universitárias. O Parecer se fundamenta, especificamente, no $\S 2^{\circ}$, do Art. 54, da LDB/1996 (BRASIL, 1996), que declara que "as atribuições de autonomia universitária poderão ser estendidas a instituições que comprovem alta qualificação acadêmica para o ensino ou para a pesquisa, com base em avaliação realizada pelo poder público".

Nesse sentido, ressalta-se que o Parecer estabelece a nota 5 nas avaliações do Inep e do SINAES como condicionamento para a autonomia das IES não universitárias, o que se atrela ao artigo exposto da LDB. Entretanto, deve-se recordar que também a nota 4 já renova credenciamentos automaticamente, como foi contestado por Polidori (2009), como fator de determinação de qualidade de ensino. De qualquer forma, tratase de um importante instrumento legal, no que toca às IES não universitárias. O fato é que com a homologação do Parecer CNE/CES 398/2019, as IES não universitárias poderão ter acesso à autonomia outorgada às IES universitárias, desde que mantenham a nota máxima nas avaliações do MEC.

Observou-se que não consta na legislação quais seriam os interesses estudantis, que os procedimentos avaliativos preservam. Não se pode analisar a lei sem perceber que, em muitos momentos, há dubiedade ou falta de objetividade na argumentação. É nesse contexto que fica constatado o tratamento diferenciado dado às Instituições não universitárias, submetidas à ausência de autonomia, mas, ao mesmo tempo, a um sistema avaliativo idêntico ao das IES universitárias.

\subsection{Autonomia e Procedimentos Avaliativos}

Pode-se afirmar que o princípio da autonomia didáticocientífica e administrativa é dado expressamente à Universidade, pela Constituição Federal, em seu Art. 207, determinando que as Universidades gozam de autonomia didático-científica, administrativa e de gestão financeira e patrimonial, obedecendo ao princípio de indissociabilidade entre ensino, pesquisa e extensão. Uma vez que a CF é a lei fundamental e suprema do Brasil, quando se reporta a LDB, encontram-se orientações complementares, que indicam a preservação do princípio constitucional. O Decreto $\mathrm{n}^{\circ}$ 9.235/2017 também aborda essa autonomia no Art. 40, prevendo a existência de limites de autonomia, considerando que a oferta de alguns cursos, entre os quais Medicina, Direito, Psicologia, Enfermagem e Odontologia, está submetida à prévia autorização. Por outro lado, a mesma lei, no Art. 39, declara que a oferta de cursos pelas Faculdades fica dependente da autorização do MEC.

A Seres determina os riscos iminentes ou as ameaças ao interesse público, incluindo dos estudantes, podendo tomar medidas cautelares, nas quais se encontram a suspensão de ingressos, de ofertas de cursos de graduação e de pós-graduação e, no inciso III, do Art. 63, também a suspensão da autonomia da IES. Essa suspensão pode ocorrer a partir, principalmente, da constatação de irregularidades administrativas, apresentadas no Art. 72, que incluem a inobservância dos atos autorizativos ou ações em desconformidades com esses, além de interrupção de aulas, por mais de dois anos, ou convalidação e aproveitamento de estudos, de forma irregular, registro inapropriado de diplomas, ausência de protocolos de credenciamento e recredenciamento, e prestação de informações inverídicas ao MEC.

A suspensão temporária da autonomia está prevista também no At. 73. É importante observar que as Faculdades não possuem a autonomia, que é outorgada às Universidades, já que para procedimentos como expedição de diplomas, deverão seguir as orientações do MEC e registrá-los junto a uma Universidade ou IES Universitária, conforme o Art. 99 do Decreto 9235/2017.

Nesse contexto, Polidori, Marinho-Araújo e Barreyro (2006, p. 426) declaram que "historicamente, a avaliação da educação superior no país tem início na década de 1970, com a instituição da política de avaliação da pós-graduação pela CAPES, especialmente voltada aos cursos de mestrado e doutorado". No que tange à graduação, a partir de 1983, o MEC criou o Programa de Avaliação da Reforma Universitária (PARU), mais voltado para a gestão das IES e a disseminação de conhecimentos, mas o programa foi desativado um ano depois, dando início a uma série de medidas governamentais, que buscavam essa avaliação, como a Comissão de Notáveis e o Grupo Executivo da Reforma da Educação Superior (GERES), de 1986.

Essa tendência avaliativa fez com que as IES, até o começo da década de 1990, dessem início a procedimentos de avaliação interna e autoavaliação, gerando comunicação com as propostas do MEC, com as IES federais e a Associação das Instituições Federais do Ensino Superior (ANDIFES), fundada em 1989.

A própria Andifes acaba subsidiando essas experiências autoavaliativas, principalmente, por meio da produção de um guia de avaliação das IES, promovendo a criação do Programa 
de Avaliação Institucional das Universidades Brasileiras (PAIUB), aplicado nos anos de 1993 e 1994, com apoio da Secretaria de Educação Superior (SESU) do MEC (POLIDORI; MARINHO-ARAÚJO; BARREYRO, 2006).

A realidade é que o 'administrar livremente' se mostra demagógico, inclusive para a atuação das Universidades. No entanto, mais que isso, qual é a racionalidade aplicada nas normatizações que diferenciam as Universidades das Faculdades no que tange à autonomia? Se as Faculdades estão submetidas às mesmas avaliações, por que essas não têm autonomia para expedir um diploma? Trata-se de trâmite relativamente simples, que, por exemplo, aumenta a carga de trabalho das IES Universitárias em função dessa ausência de autonomia das IES não Universitárias. Pode-se perceber que a diferenciação entre as Instituições está na abrangência da sua atuação, e foi apontado que, em ambos os casos, as IES estão submetidas aos atos autorizativos e aos procedimentos avaliativos do MEC.

Sendo assim, é pertinente questionar: por que a Faculdade isolada é tratada como exceção no sistema educacional brasileiro, embora tenha sido a origem de muitas das atuais Universidades? No âmbito do desenvolvimento da educação e, em especial, do Ensino Superior no Brasil, pode-se perceber que a instituição Faculdade, especialmente a privada, é necessária dentro das políticas públicas de expansão do ensino, mas não se pode ignorar que o Estado mantém o controle, por meio dos procedimentos avaliativos, contornando a exposição

à democracia, conforme havia sido promulgada na Carta Magna de 1988. O que acontece, então, é uma liberalização em alguns momentos, cerceada em outros momentos, por meio de aparatos legais, mantendo-se o controle estatal dessa oferta e, também, da demanda do mercado. Não se crê que se possa realmente considerar que a Faculdade isolada seja ignorada pela lei nacional, mas, antes disso, parece mais provável que essas instituições funcionam como títere do Estado, e as avaliações são as cordas que guiam os movimentos desses títeres.

Tendo em vista que as normas impõem para ambas as instituições (Universitárias e não Universitárias) os mesmos critérios legais de credenciamento, a lógica da determinação de autonomia para Universidades e seu indeferimento para Faculdades parece não possuir um respaldo de critérios que realmente sustentem qualquer alegação. Também, nesse sentido, é importante recordar a diferença de tempo para recredenciamentos ou renovação dos atos autorizativos, já que IES Universitárias têm dez anos de prazo, e as Faculdades, a metade, devendo arcar, portanto, com o dobro dos valores para a visita in loco.

Polidori (2009, p. 446) declara que "a proposta do SINAES compreende a necessidade de as IES passarem por um ciclo completo de avaliação". Ainda assim, esse ciclo não deve ser considerado de modo linear, já que cada um dos pilares apresenta estágios diversificados em cada IES. Daí a necessidade de se respeitar as especificidades de cada uma dessas. Polidori, Marinho-Araújo e Barreyro (2006, p. 434) declaram que o SINAES representa um avanço dos procedimentos avaliativos da Educação Superior brasileira, que antes "promovia o ranking e a competitividade, baseado em estratégias de visibilidade mercadológica, para um paradigma que propõe a avaliação formativa ao incluir a autoavaliação participativa nas instituições e propor sua articulação com a regulação do sistema".

Além disso, declaram que um grande desafio do SINAES é "articular as necessidades regulatórias com os tempos requeridos à construção de uma cultura da avaliação nas instituições" (POLIDIRI; MARINHO-ARAÚJO; BARREYRO, 2006, p. 435). Crê-se que, talvez, seja pertinente questionar se a cultura da avaliação e sua consolidação demonstram alguma diferenciação com o anterior paradigma avaliativo promotor dos rankings e da competitividade entre as IES e os profissionais e estudantes que dessas fazem parte e, mais que isso, se realmente a suposta autoavaliação teve o poder de destituir essa competitividade e os rankings. Não são esses ainda estabelecidos?

Como afirma Ferronato (2016), a questão da avaliação assume outros contornos quando o Estado ou seus órgãos avaliadores utilizam a avaliação como instrumento de decisão para outorgar ou não credenciamentos, recredenciamentos, renovações de permissão para funcionamento, e outros atos autorizativos. A avaliação pensada dessa forma se torna centralizadora e, embora forneça um panorama eficiente de informações científicas, produção e atividades desenvolvidas, gera tensões, fundamentadas, principalmente, no bojo dessas discussões, a respeito da centralidade do SINAES e no seu foco nos resultados, mais que na busca real pela melhoria da qualidade das IES.

Em 2008, foi apresentado o CPC, constituído em seu valor total, a partir de percentuais dos insumos atribuídos, relativos às instalações físicas da IES (30\%), do ENADE (40\%), e do IDD (30\%). No que toca à questão dos insumos, ainda acontece uma distribuição de peso da nota, expandido entre infraestrutura, recursos didático-pedagógicos, titulação do corpo docente e regime de trabalho. Uma parte das informações é extraída dos estudantes, ao realizarem as provas do Enade, e outra parte mediante as informações prestadas pelas próprias IES no ato dos cadastros de docentes. Nesse cenário, quando os cursos apresentam pontuação de 1 a 2 no Enade, receberão, obrigatoriamente, a visita da comissão avaliativa. Se a nota estiver entre 3 e 4 essa visita é opcional. E quando a nota se apresenta entre 4 e 5, as Portarias de renovação são geradas, automaticamente, pela SESU e SETEC, segundo a natureza de cada curso.

Polidori (2009) aponta para certa distorção na composição da nota do indicador, principalmente, porque a nota do Enade acaba determinando, imediatamente, a qualidade da IES e sua possível renovação automática, o que contraria os princípios do próprio SINAES, na medida em que somente um dos seus pilares já é determinante e, além disso, as informações acerca 
da infraestrutura e recursos pedagógicos são obtidas das respostas dos estudantes no Enade. Nesse sentido, "apresenta-se, aqui, um grande equívoco em termos de aplicabilidade do SINAES na sua proposta conceitual, a partir do uso de um único pilar do Sistema como o definidor de qualidade da educação superior oferecida pelas IES" (POLIDORI, 2009, p. 447).

O ENADE, deve-se ter em mente, fundamenta-se nos conteúdos programáticos expostos nas Diretrizes Curriculares Nacionais, a fim de captar o grau de aprendizagem dos estudantes com relação a esse conteúdo, em cada área de formação e curso, avaliando as habilidades e competências; enquanto a avaliação in loco aborda muitas outras questões

à parte de uma nota que visa a mensurar a aprendizagem dos estudantes.

A ideia de que a nota máxima do Enade dispensa a avaliação in loco e outorga a renovação irrestrita dos atos autorizativos significaria que aquela IES, certamente, possui um Projeto de Autoavaliação Institucional eficiente, com a participação da comunidade e com a divulgação de resultados e todos os demais requerimentos do eixo 1? Nesse caso, as divergências administrativas, que podem destituir a autonomia são consideradas já previamente inexistentes. Enfim, o que acontece é que a IES é avaliada, primeiramente, pela nota dos alunos. Essa é a nota decisiva e capaz de eliminar muita burocracia.

Além disso, importa ressaltar que o trabalho de Ferronato (2016) aponta que a implementação do SINAES e de todas as medidas legislativas decorrentes desse acabaram por colocar um sistema ou procedimento avaliativo no centro da política pública educacional brasileira, um comportamento atrelado às questões de ordem empresarial. Essa política pública da avaliação, com seu conceito de legalidade é motivo para se adotar uma atitude crítica acerca de todo o sistema educativo, a fim de se incentivarem reflexões, e não apenas para apontar falhas.

\section{Conclusão}

No decorrer deste trabalho foi apresentado o histórico de implantação das Universidades no Brasil e contexto atual das normativas associadas ao Ensino Superior e às IES. Foi possível averiguar que no desenvolvimento e na formação da instituição Universidade, as Faculdades assumiram um papel fundamental, sendo que as primeiras leis indicavam que uma Universidade seria consolidada, a partir da junção das Faculdades de Direito, Medicina e Engenharia. Pese a todo o processo de desvalorização da educação no Brasil, o Ensino Superior começa seu desenvolvimento para a manutenção das elites nacionais, que não mais querem buscar Educação na antiga metrópole.

Além disso, é importante ressaltar que as instituições privadas, de cunho religioso ou não, sempre tiveram grande importância na educação nacional, e que o maior desenvolvimento da Educação Superior ocorreu após a implementação das políticas liberalistas do começo do século
XXe, mais especialmente, das políticas neoliberais das últimas décadas daquele século. Houve dois grandes momentos de expansão do Ensino Superior, sendo ambos fundamentados no setor privado, o que transformou a Educação em uma mercadoria.

Entretanto, o Estado como controlador implementa, junto com as políticas neoliberais, os sistemas avaliativos de controle, sob o argumento da busca constante pela melhoria da qualidade. Não que se possa afirmar que tal argumento seja falacioso, mas, por outro lado, foi possível constatar, neste trabalho, que as propostas avaliativas das IES são desiguais e apresentam falhas, como a questão discutida da nota Enade e renovação automática de atos autorizativos, e como a própria desigualdade de se manter o mesmo sistema avaliativo para instituições, que possuem e que não possuem autonomia administrativa, didática e financeira.

No decurso deste artigo também foi possível analisar aspectos teórico e legais, que envolvem a estrutura organizacional e os procedimentos avaliativos propostos pelo MEC. Também foi possível apontar, de maneira crítica, a estruturação do SINAES, do Enade, a inter-relação com o credenciamento das IES, e o desenvolvimentos de procedimentos avaliativos e plataformas, que buscam a evolução na Educação, mas muitas vezes acabam representando entraves. Percebeu-se que as IES não Universitárias, ou seja, Faculdades estão submetidas ao mesmo procedimento avaliativo das IES Universitárias, muito embora seus direitos sejam diferentes com relação, especialmente, à autonomia, ao credenciamento e ao recredenciamento, reconhecimento de cursos, e outros atos autorizativos, sendo que, para além dessa desigualdade, as Faculdades acabam arcando com maiores despesas financeiras, já que seu tempo de credenciamento é mais curto.

Essa desigualdade indica que a aplicação dos instrumentos do Inep sobre as Faculdades não respeita a identidade institucional, mesmo quando essas IES cumprem com todos os quesitos para a sua permanência no mercado.

Este trabalho teve como objetivo analisar o impacto da aplicação do instrumento de avaliação institucional emitido pelo INEP nas Faculdades, verificando a adequação da realidade institucional e averiguando até que ponto esse instrumento de avaliação externa favorece a emancipação e autonomia das Faculdades.

Diante de todas as perspectivas apresentadas e discutidas foi possível concluir que a aplicação da avaliação institucional do Inep apresenta características subjetivas e de desigualdade,

especialmente, porque configura contradições quanto à nota do Enade como um fator de renovação imediata de ato autorizativo e, ainda, por que na medida em que todas as IES estão submetidas à determinados padrões dos eixos de avaliação, torna-se superficial a questão do respeito à diversidade institucional. Acerca da autonomia e da emancipação, foi possível constatar que as Faculdades são submetidas à mesma condição avaliativa, embora não 
possuam autonomia de acordo com a legislação brasileira.

Alguns processos operacionais, que tramitam entre a

IES e Ministério da Educação, têm passado por adequações no sentido de atribuir às Instituições não Universitárias autonomia didático-pedagógica e administrativa. Há proposta de mudança dessa situação, mas, igualmente, tal proposta se atrela às questões avaliativas e de resultados alcançados pelas IES, e não nos preceitos democráticos de que, enquanto Instituição Educacional, uma Faculdade deveria ter direitos equivalentes às Universidades para a emissão de diplomas, aumento da oferta de vagas, e outras questões que deveriam ser resolvidas de forma rápida e simplificada, mas acabam presas pelas burocracias do controle estatal.

\section{Referências}

BORTOLANZA, J. Trajetória do Ensino Superior brasileiro - uma busca da origem até a atualidade. In: COLÓQUIO INTERNACIONAL DE GESTÃO UNIVERSITÁRIA, 2017. Mar del Plata, Argentina, 22-24 nov. 2017.

BRASIL. Lei $n^{\circ}$ 9.394, de 20 de dezembro de 1996. Estabelece as diretrizes e bases da educação nacional. Brasília, 1996.

BRASIL. Decreto n. 3.860, de 9 de julho de 2001. Dispõe sobre a organização do ensino superior, a avaliação de cursos e instituições, e dá outras providências. Brasília, 2001.

BRASIL. Lei n. 10.861, 14 de abril de 2004. Institui o Sistema Nacional de Avaliação da Educação Superior - SINAES e dá outras providências. Brasília, 2004a.

BRASIL. Decreto n. 10.870, de 19 de maio de 2004. Institui a Taxa de Avaliação in loco das instituições de educação superior e dos cursos de graduação e dá outras providências. Brasília, 2004b.

BRASIL. Decreto n. 5773, de 9 de maio de 2006. Dispõe sobre o exercício das funções de regulação, supervisão e avaliação de instituições de educação superior e cursos superiores de graduação e sequenciais no sistema federal de ensino. Brasília, 2006.

BRASIL. Decreto n. 9.235, de 15 de dezembro de 2017. Dispõe sobre o exercício das funções de regulação, supervisão e avaliação das instituições de educação superior e dos cursos superiores de graduação e de pós-graduação no sistema federal de ensino. Brasília, 2017.

BRASIL. E-MEC. Perguntas Frequentes. 2019 [online]. Disponível em: <http://emec.mec.gov.br/> Acesso em 12 jun. 2019.

BRASIL. Ministério da Educação. Portaria n. 21, de 21 de dezembro de 2017. Dispõe sobre o sistema e-MEC, sistema eletrônico de fluxo de trabalho e gerenciamento de informações relativas aos processos de regulação, avaliação e supervisão da educação superior no sistema federal de educação, e o Cadastro Nacional de Cursos e Instituições de Educação Superior Cadastro e-MEC. Brasília, 2017.

BRASIL. Ministério da Educação. PARECER CNE/CES N ${ }^{\circ}$ 398/2019. Regulamentação do $\S 2^{\circ}$ do Art. 54 da Lei de Diretrizes e Base da Educação Nacional (Lei no 9.394/1996), para permitir que instituições que não possuam o status de Universidades venham a ter as prerrogativas equivalentes a elas, por alta qualidade acadêmica. Brasília, 2019a.

BRASIL. Ministério da Educação. PORTARIA No 748, DE 23 DE AGOSTO DE 2019. Institui a Comissão de Assessoramento para Revisão dos Processos Avaliativos, Instrumentos e Técnicas de Coleta de Dados e Indicadores da Educação Superior do Instituto Nacional de Estudos e Pesquisas Educacionais Anísio Teixeira (Inep). Brasília, 2019b.

FÁVERO, M.L.A. A Universidade no Brasil: das origens à Reforma Universitária de 1968. Educar, n.28, p. 17-36, 2006.

FERRONATO, F.B. Interfaces entre avaliação institucional e gestão de instituições de Ensino Superior: um estudo a partir do SINAES. Pouso Alegre: Universidade do Vale do Sapucaí, 2016.

FOUCAUT, M. Estratégia, poder-saber. Rio de Janeiro: Forense Universitária, 2006.

GOLDENBERG, M. A arte de pesquisar: como fazer pesquisa qualitativa em ciências sociais. Rio de Janeiro: Record, 2004.

HUMEREZ, D.C.; JANKEVICIUS, J.V. Evolução histórica do Ensino Superior no Brasil. 2015. Disponível em: <http://www. cofen.gov.br/enfermagem- e-formacao-artigoscientificos_31492. html > Acesso em: 10 jun. 2020.

INEP - Instituto Nacional de Estudos e Pesquisas Educacionais Anísio Teixeira. Censo da Educação Superior. Notas estatísticas 2017. Brasília: INEP/MEC, 2017.

KOGA, Y.M.N.; GUINDANI, E.R. Educação e neoliberalismo: interferências numa relação tirânica. Rev. Simbiótica, v.4, n. 2, 2017.

NEVES, C.E.B.; MARTINS, C.B. Ensino Superior no Brasil: uma visão abrangente. DWYER, T. et al (Org.). Jovens universitários em um mundo em transformação: uma pesquisa sino-brasileira. Brasília: Ipea; Pequim: SSAP, 2016. p.95-124.

POLIDORI, M.M. Políticas de avaliação da educação superior brasileira: Provão, SINAES, IDD, CPC, IGC e... outros índices. Avaliação, v.14, n.2, p.439-452, 2009.

POLIDORI, M.M.; MARINHO-ARAÚJO, C.M.; BARREYRO, G.B. SINAES: perspectivas e desafios na avaliação da educação superior brasileira. Ensaio Aval. Pol. Públicas Educ., v.14, n.53, p.425-436, 2006.

SAMPAIO, H. Evolução do ensino superior brasileiro, 18081990. São Paulo: Núcleo de Pesquisas sobre Ensino Superior, 1991.

SAMPAIO, H. Ensino Superior no Brasil: o setor privado. São Paulo: Fapesp/Hucitec, 2000.

SAMPAIO, H. O setor privado de ensino superior no Brasil: continuidades e transformações. Rev. Ensino Superior Unicamp, p.28-43, 2011.

SÁ, E.F.; MONTEIRO, S.B. Universidade Federal de Mato Grosso: da regionalização à internacionalização. Educativa, v.20, n.1, p.253-267, 2017.

SCHWARTZMAN, S. A sociedade do conhecimento e a educação tecnológica. Trabalho realizado por solicitação do Serviço Nacional de Aprendizagem Industrial - SENAI, Departamento Nacional. 2005. Disponível em: https://www.ufrb.edu.br/ educacaodocampocfp/images/2005_senai.pdf

SILVA, T.P.; SUANNO, M.V.R. Influência das políticas neoliberais nas Instituições de Ensino Superior. In: EDUCERE - CONGRESSO NACIONAL DE EDUCAÇÃO. PUCPR, Curitiba, 26-29 out. 2015.

SINAES. Instrumento de Avaliação Institucional Externa. Brasília: INEP/MEC, 2017.

STALLIVIERI, L. O sistema de Ensino Superior do Brasil. Características, tendências e perspectivas. 2006. Disponível em: $<$ https://www.ucs.br/site/midia/arquivos/sistema_ensino_ superior.pdf $>$. Acesso em: 10 jun. 2020. 
